\title{
Development and promotion research of the College foreign language teachers' language appraisal literacy (LAL)
}

\author{
Xin Guo \\ Inner Mongolia Agricultural University, Hohhot, 010019, China
}

Keywords: College foreign language teachers, Language appraisal attainment, Teachers' development.

\begin{abstract}
Language assessment literacy refers to foreign language teachers' familiarity with foreign language testing theories. College foreign language teachers should spend a large amount of professional time on activities related to language testing assessment, and use assessment results to feedback teaching and improve teaching. Teachers' language appraisal literacy determines the quality of language assessment which is related to teaching quality. This article has organized the definition of language appraisal attainment, domestic and foreign relevant researches, and emphasized the importance of developing college foreign language teachers' language assessment literacy and discussed the effective promotion approaches.
\end{abstract}

\section{Introduction}

Language appraisal literacy refers to the assessment knowledge and skills requiring foreign language teachers to master in a broad sense. College foreign language teachers have universally participated in appraisal practice. They can compile summative assessment for reporting students' learning performance and can proceed formative evaluation for the purpose of promoting study. In addition, they need to use appraisal to stimulate students and improve teaching. Thus, teachers' language appraisal literacy is closely related to teaching quality. On the basis of organizing the research condition of domestic and foreign language appraisal attainment, this article has pointed out that Chinese college foreign language teachers must pay attention to the cultivation and promotion of language appraisal attainment.

\section{Current research status of language appraisal attainment}

Before summarizing the research situation of domestic and foreign language appraisal attainment, it is necessary to define the appraisal literacy and language appraisal attainment. Studies on language appraisal literacy in foreign countries originate from researches on teachers' assessment ability.

\section{Definition of teachers' appraisal literacy}

Teachers' appraisal literacy also called evaluating ability is not yet uniformly defined in education evaluation field. Researchers have described appraisal literacy of evaluating ability from different perspectives. Stiggins (1995) believed that from the perspective of appraiser, an eligible appraiser should be clear about the assessment purpose and select effective assessment methods for testing and assessment activities. Popham (2009) pointed out that appraisal literacy should be inspected from two levels, ability and knowledge and should consider the influence of morals and ethics. Thus teachers should master the knowledge of education estimation so as to design and implement appraisal and analyze appraisal results. Meanwhile, they should find and timely remove appraisal bias, and know methods of appraisal on special groups such as disabled students. Brookheart (2011) has listed 11 items of knowledge and skills of education appraisal literacy from the perspective of classroom 
testing and assessment, including teachers' choices, development and abilities of implementing classroom appraisal, also including close relationship between classroom testing and teaching target. To sum up, education estimation field believes that appraisal as an important component can feedback teaching and be used for teaching. Thus teachers' appraisal literacy is closely related to teaching quality.

\section{Definition of language appraisal attainment}

In recent years, teachers' appraisal literacy research has received attention from pedagogy field and attention from linguistic domain. Language appraisal literacy refers to language teachers' mastery of appraisal methods and their ability to apply appraisal knowledge to classroom practice (Malone 2013). Also language testing is different with other subject testing because language is a testing tool and the subject to be estimated. LAL is closely related to appraisal theories mastered by teachers. Some scholars have noticed that language teachers will be influenced by language teaching theories that they have known. For example, teachers value traditional grammar teaching will apply the appraisal method of clocking composition and give feedbacks based on grammar; teachers with constructivism will apply the method of students' mutual judgement; teachers focusing on the social and culture oriented language will tend to get students participated in designing team composition and scoring criterion. Some teachers defining teachers' professional start from the perspective of social culture, and emphasize that language appraisal literacy should also include teachers' reflection and awakening on their appraisal role (Scarino 2013). Thus, language teachers' appraisal literacy contains teachers' understanding of theories and knowledge of language related domains, familiarity of appraisal contents, and the ability to know how to evaluate and master the background and reasons of appraisal behaviors.

From the perspective of pedagogy or linguistics, appraisal literacy is defined to emphasize that teachers should be equipped with good appraisal awareness, appraisal knowledge and skills, and should reasonably analyze appraisal results for teaching feedback. This is a process that teacher continuously rethink the relationship between pedagogy and teaching practice so as to improve teaching quality, as well as the only way for teachers to perfect own professional growth.

\section{Research status of domestic and foreign language appraisal literacy}

Studies on teachers' appraisal literacy at home and abroad started from 1990s. In the year of 1990, AFT and American National Education Estimation Association and National Education Association has jointly formulated relevant occupational standard on teachers' appraisal ability, and published "Teachers' ability standard of students' educational appraisal" which required teachers to have abilities of seven aspects, and specifically indicated appraisal knowledge and skills that teachers should proficiently master, thus it has been recognized by a lot of scholars and widely used as the important basis for teachers' appraisal literacy investigation. In 1993, Plake, etc. have pioneered investigation and research on teachers' appraisal literacy. Based on the standard, they have designed teachers' appraisal attainment questionnaire and conducted the questionnaire survey on more than 500 primary and middle school teachers in different places of US. Studies show that appraisal literacy of in-service teachers are generally in a low level. In 2004, EU has initiated surveys on European foreign language teachers' current foreign language testing knowledge and training demands. In 2008, the 5th Annual of ALTE has specially discussed the current status and future of foreign language teachers' LAL in Europe and other countries. Association members started focusing on the development target of foreign language teachers' LAA in their own countries. In 2013, the third special issue of Language Testing has reported the important meeting achievements of "the 33rd Annual of ALTE": LAL. Thus foreign language teachers' LAL has received more attention. Generally speaking, a large amount of thorough researches on LAL have been done in foreign countries.

China is slightly lagged behind in the time of study on LAL compared with foreign countries. Wang Shaofei (2007) is the one of the earliest people discussing teachers' LAL at home. He has indicated the necessity of improving teachers' appraisal professional literacy in the fifth chapter of his doctorate paper "Studies on school-based examination monitoring" but did not mention LAL. Lin 
Dunlai (2011) has discussed the construction and cultivation of LAL. Xu Yueting (2013), Meng Lan (2016) and other scholars have conducted studies on Chinese foreign language teachers' LAL from different perspectives. It can be seen that domestic studies on teachers' appraisal literacy are scattered in a small amount but LAL has gradually aroused the attention from the field of teachers' education and scholars in linguistic field. Relevant studies will keep receiving more attention from domestic scholars.

\section{College foreign language teachers' LAL development and promotion approaches}

Appraisal literacy influences the effect and efficiency of teaching as the important contents of college foreign language teachers' occupational skill development. Considering this, this article discuss approaches of LAL improvement.

\section{Teacher training and advance with the times}

Currently, even Chinese college foreign language teachers are in short of foreign language appraisal knowledge, for pre-service training and in-service education, China still under emphasizes the training of college foreign language teachers' appraisal. Bedsides, current training course cannot reflect the new type language teaching assessment concept and techniques. Some scholars have taken investigations and researches on 86 appraisal courses in China. Results show that more than 80\% courses are in the name of "language testing" but course title seldom includes "evaluation" or "appraisal", teaching contents are mainly about appraisal knowledge and contents lacking systematic introduction of new type education system which focuses on promoting learning effect (Jin 2010). Thus, LAL relevant training should advance with the times from the course R \& $\mathrm{D}$, and teaching methods to make some changes.

Firstly, from the perspective of course R \& D, it is necessary to embed classroom assessment training into language teachers' training program planning. Classroom assessment focuses more on students' learning process as a summative evaluation usually used in colleges and an effective supplement of large-scale final exam as its function of learning promotion has been widely used in college foreign language classroom. Language appraisal courses set in China now only focuses on language testing to carry out teaching without focus on classroom assessment. Thus, in foreign language teachers' training courses, it is very necessary to add new classroom assessment course or add classroom assessment related contents into current language appraisal courses. Meanwhile, in teaching materials, teacher educators should formulate training manual based on the latest research achievements and combine multimedia together with sound video and other materials to get language teachers exposed to living examples of language classroom assessment practice and arouse foreign language teachers' to practice and think based on their own teaching estimation so as to improve their own ability in classroom assessment.

Secondly, from the perspective of instructing method, teacher educators should dare to attempt new instruction ways. Currently, college classrooms usually emphasizes changing traditional teaching centered class into student-centered class. Teacher training should be the same. In teacher training, teacher educator should get teachers as the course leader and fully get them participated in setting questions, practicing and discussing results, and using portfolio method in course appraisal. This new type instruction way can effectively improve teacher trainees' class participation and the mastery of appraisal knowledge so that the training effect has been improved. We can say that the method of teacher education is actually complement with the new type education assessment advocated in colleges now. Teacher educators focus on the individual differences between teacher trainees, pay attention to their learning demands, and get them fully participated in appraisal training courses, use mutual judgement, self-evaluation and other classroom assessment methods to promote mutual cooperation between teacher trainees to improve their appraisal ability in practice.

\section{Other approaches}

Except for abovementioned official college teacher education course training, workshop, seminar, expert instruction, teachers' team for mutual aid, and self-learning based on materials can promote the 
development and improvement of college English language teachers' appraisal literacy. College on-duty foreign language teachers can attempt to establish learning teams and enrich their knowledge in appraisal literacy through mutual communication between colleagues. Overseas colleges have boldly attempted to put on-duty teachers and pre-service teachers in one group to learn appraisal theoretical knowledge. This kind of group learning can compensate the flaws of inexperienced appraisal practice and can also provide chances for on-service teachers who have never learned appraisal theories. In addition, college foreign language teachers can improve their appraisal literacy. In fact, a lot of teachers' appraisal ability are obtained with the help of continuous self-learning, practice and reflection. Foreign teachers can make full use of their own language competence, search and learn foreign latest LAL related academic articles and materials on the internet, etc. To sum up, there are a lot of language appraisal ability development ways. College foreign language teachers should have a lifelong learning attitude to appraisal literacy development and promotion, continuously update language subject knowledge and language appraisal knowledge, and keep rethinking based on practical conditions.

\section{Conclusion}

It's worth noting that in language appraisal research domain, foreign teachers' LAL in the early stage emphasized summative assessment purpose, method and the requirement for interpreting appraisal results, and then it changed to focus more on how teachers use formative assessment to guide teaching and promote students' learning. Currently, college students' appraisal literacy has received attention day by day. The development of college foreign teachers' LAL relates to the improvement of teaching quality and the development of teachers' own professionalism. Teacher educators and relevant researchers should strengthen studies on LAL course effect, enhance the guidance for language teachers on specific appraisal practice. Meanwhile, college foreign teachers should have a lifelong attitude, update their own appraisal knowledge and keep learning and rethinking in appraisal practice to further develop and improve their own LAL.

\section{References}

[1] Brookhart S. Educational assessment knowledge and skills for teachers, Educational Measurement: Issues and Practice, 2011, 30(1), pp.3-12.

[2] Jin Y. The place of language testing and assessment in professional preparation of foreign language teachers in China, Language Testing, 2010, 27(4), pp.555-584.

[3] Malone M. The essentials of assessment literacy: Contrasts between testers and users, Language Testing, 2013, 30(3), pp.329-345.

[4] Plake B S, Impara J C\& Fager J J. Assessment competencies of teachers: A national survey, Educational Measurement: Issues and Practice, 1993, 12(4), pp.10-12,39.

[5] Popham W J. Assessment literacy for teachers: Faddish or fundamental? Theory into Practice, 2009, 48(1), pp.4-11.

[6] Scarino A. Language assessment literacy as self-awareness: Understanding the role of interpretation in assessment and in teacher learning, Language Testing, 2013, 30(3), pp.309-327.

[7] Stiggins R J. Assessment literacy for the 21st century, phi Delta Kappan, 1995, 77(3), pp.328-336.

[8] Lin Dunlai. Teachers' appraisal literacy: theory and practice, Foreign Language Teaching | Fore Lang Teach, 2011 (4), pp.29-37.

[9] Meng Lan. Exploration of college English teachers' appraisal literacy promotion mode, Journal of Xi'an International Studies University, 2016 (6), pp.72-76.

[10]Xue Yueting. Research summary of foreign language teachers' classroom appraisal quality, 
Foreign Language Testing and Teaching, 2013 (4), pp.42-50.

[11]Wang Shaofei. Studies on school-based monitoring, Shanghai: East China Normal University, 2007, pp.101-127. 